\title{
A New Isoelectric Focusing System for Fast Two-Dimensional Gel Electrophoresis Using a Low-Concentration Polyacrylamide Gel Supported by a Loose Multifilament String
}

\author{
Jinxiang LI,* Ayaka OgaSawara, ** Tamao Odake, ${ }^{* * \dagger}$ Tomonari Umemura, ${ }^{* *}$ and \\ Kin-ichi TSUNODA** \\ *Department of Chemistry, Liaoning Normal University, 850 Huanghe Road, Dalian 116029, China \\ **Department of Chemistry, Faculty of Engineering, Gunma University, 1-5-1 Tenjin-cho, \\ Kiryu, Gunma 376-8515, Japan
}

\begin{abstract}
A new isoelectric focusing (IEF) system for two-dimensional polyacrylamide gel electrophoresis (2-D PAGE) has been proposed. In this system, a super-soft and tough IEF gel was achieved by casting polyacrylamide gel down to $2.0 \%$ T using a loose multifilament string (LMS) of nylon as a gel support. The IEF apparatus for the LMS-gel, fabricated from acrylic boards, had a cooling water chamber, and eliminated the need of electrode solutions by directly connecting the two ends of individual gels to platinum electrodes. The carrier ampholyte-generated $\mathrm{pH}$ gradients using the new IEF system was stable over a long duration of time and a wide range of voltages, and the IEF time became shorter using a $2.0 \% \mathrm{~T}$ gel than using a $4.0 \% \mathrm{~T}$ gel. Also, the LMS-gels prepared in different runs exhibited excellent reproducibility. The new IEF system was applied to 2-D PAGE of a chicken skeletal muscle extract, and it was found that the protein loading capacity, protein entry into the LMS-gels, and protein transfer efficiency from the first-dimensional to the second-dimensional gels were significantly improved by using a low-concentration $(2.5 \% \mathrm{~T})$ gel. Also, proteins of high molecular weight of more than $200 \mathrm{kDa}$ were observed in the 2-D maps, and therefore the new IEF system has a very good potential to be applied for fast 2-D PAGE of high molecular-weight proteins.
\end{abstract}

(Received September 9, 2004; Accepted October 25, 2004)

\section{Introduction}

Two-dimensional gel electrophoresis (2-DE) is a powerful separation technique for proteome analysis because of its extremely high resolution. Though this technique has undergone many methodological and instrumental improvements, especially in the first-dimensional isoelectric focusing (IEF), over the past 29 years since its first description in $1975,{ }^{1}$ it still suffers from many limitations. ${ }^{2,3}$ One of the main limitations is a long analysis time, typically 2 days. Especially the first-dimensional IEF needs overnight, and has become a bottleneck step of 2-DE. Another main limitation of 2-DE is poor performance in detecting large, insoluble proteins, such as membrane proteins. These proteins are prone to be lost during application to the IEF gel, during focusing at, or near to, their pIs, and during their transfer from first-dimensional to second-dimensional gels..$^{2-16}$

Enlarging the IEF gel pore size is the simplest and most effective approach to fasten IEF separation and to improve the performance in detecting large and insoluble proteins. For one example, by using agarose gels of large pore size in the first dimension, Hirabayashi ${ }^{10}$ and Oh-Ishi" ${ }^{9,11}$ et al. separated "almost all of the proteins" of chicken skeletal muscle, including large proteins, such as myosin heavy chains ( $c a .200 \mathrm{kDa}$ ), which were not found in the 2-D maps when using polyacrylamide gel

$\doteqdot$ To whom correspondence should be addressed.

E-mail: odake@chem.gunma-u.ac.jp in the first dimension..$^{910}$ However, it is well known that agarose gels suffer from a severe electroendosmotic effect during IEF, which can result in a poor reproducibility of 2-D protein maps. For another example, Candiano et al. ${ }^{6}$ reported that a 2 - 3 times higher staining density of proteins on 2-D maps was obtained by simply diluting the gel matrix, normally composed of $4 \% \mathrm{~T}$ polyacrylamide, down to $3.3 \% \mathrm{~T}$. However, they had to give up further dilution of the gel because the gels below $3 \% \mathrm{~T}$ were extremely difficult to handle in practice.

In this work, we concentrated on obtaining polyacrylamide gels with larger pore size by diluting the gel to a lower concentration. The currently used polyacrylamide gels for IEF are roughly divided into two strategies: one is the classical "tube gels" and the other is "strip gels". The latter are now sufficiently convenient because they are ready-made and commercially available with a wide selection of length and $\mathrm{pH}$ range. However, the lowest concentration of the polyacrylamide is $4 \% \mathrm{~T}$, though the strip gel is supported by a film. The former gel has to be made by each user, and is still subject to handling problems and irreproducibility because of its many manually intensive steps. At the end of the IEF, for example, the gel must be mechanically extruded out of the tube prior to the following steps. The force needed to extrude the focused gel from its glass tube housing is sufficient to cause compression in the axial direction. ${ }^{17}$ Furthermore, the gel has to suffer from additional tensile forces several times in the following steps before it is finally located at its position on the second-dimensional gel, and these tensile forces may elongate and/or even break the gel. To ensure pattern reproducibility, 


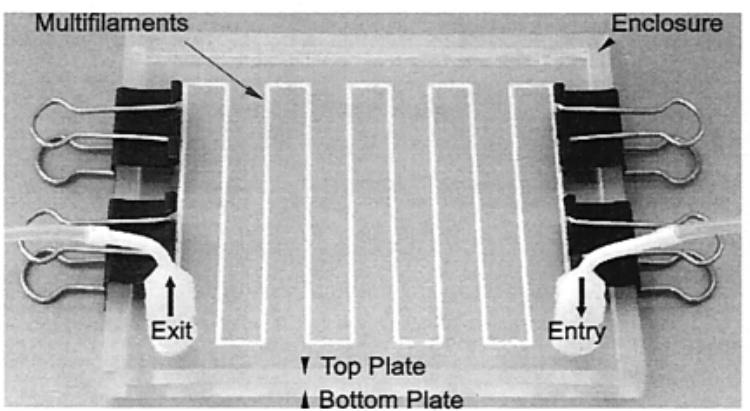

Fig. 1 Setup for the preparation of LMS-gels.

any forces possibly resulting in the IEF gel breakage and changes in dimension are undesirable.

To obtain lower concentration polyacrylamide with sufficient mechanical strength, we conceived an idea of using a loose multifilament string (LMS) as a gel support. The multifilament string can involve gel solution in and around itself, and is expected to provide a long and thin LMS-gel after polymerization.

In the present study, we proposed an LMS-gel as a novel IEF gel. The LMS-gel was prepared by casting polyacrylamide gel down to $2 \% \mathrm{~T}$ along an LMS of nylon using a home-made setup. In addition, a novel IEF apparatus for the LMS-gels was fabricated of acrylic boards that did not require electrode solutions. The IEF time and the stability of the $\mathrm{pH}$ gradient generated along the LMS-gels were examined, and the migration speed of proteins in LMS-gels was compared between gels of different concentrations. Furthermore, LMS-gels were applied to 2-D PAGE of a chicken skeletal muscle extract.

\section{Experimental}

\section{LMS-gel preparation}

To prepare LMS-gels, an LMS-gel fabrication apparatus was constructed as shown in Fig. 1. The bottom plate, the top plate and the enclosure were made of acrylic boards ( $5 \mathrm{~mm}$ thick). A long groove (1.2 mm wide, $1.2 \mathrm{~mm}$ deep, and $120 \mathrm{~mm}$ long) was machined on the bottom plate, and an inlet and an outlet were opened on the top plate. The enclosure was attached to the bottom plate around three sides of the bottom plate, and used to confine the top plate to its position. For preparing super-soft and tough LMS-gels, a loose multifilament Lily yarn of nylon, which was obtained by removing a cotton part of the knitting yarn (Gommone, RICH MORE Brand), was used to support and strengthen the low-concentration polyacrylamide gels. Strings of proper length were accommodated in the groove, and then covered with the top plate. The bottom and top plates were tightly hold together with clips. Nitrogen gas was blown into the groove from the inlet and allowed to escape from the outlet for several minutes. This purging was necessary to remove the oxygen, which interferes with polymerization, from the grooves. An acrylamide solution of the desired concentration $(2-4 \% \mathrm{~T}$, $5.4 \% \mathrm{C}$ ) was prepared in distilled water and degassed by a vacuum. After proper amounts of $\left(\mathrm{NH}_{4}\right)_{2} \mathrm{~S}_{2} \mathrm{O}_{8}$ and $N, N, N^{\prime}, N^{\prime}$ tetramethylethylenediamine (TEMED) were added into the degassed solution, the gel solution was slowly injected through the groove with a syringe, and allowed the gel solution in the groove to polymerize for a minimum of $1 \mathrm{~h}$. After polymerization, the top plate was removed by slowly slipping it off the bottom plate from the open side of the enclosure. The

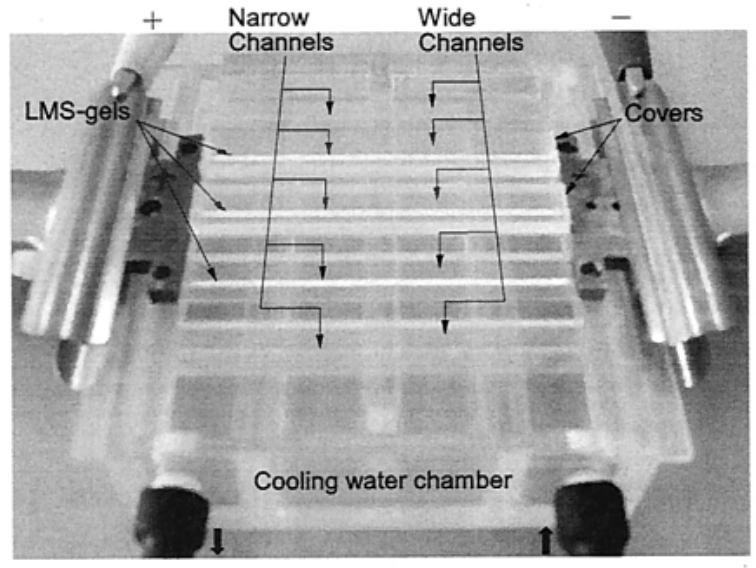

Fig. 2 Apparatus for IEF using LMS-gels.

polymerized LMS-gels were transferred into distilled water with a pair of tweezers, and soaked there for at least $1 \mathrm{~h}$. This soaking was necessary to eliminate any free ions in the gels. Finally, the soaked gels were incubated with a solution containing carrier ampholytes (CAs) for at least $1 \mathrm{~h}$. Prior to use for IEF, the incubated LMS-gels were cut into sections of proper length, $7.1 \mathrm{~cm}$ in the present study.

\section{IEF using LMS-gels}

A laboratory-made IEF apparatus for the LMS-gels is shown in Fig. 2. The apparatus was made mainly of acrylic boards (5 $\mathrm{mm}$ thick). Five wide channels ( $10 \mathrm{~mm}$ wide, $2 \mathrm{~mm}$ deep, and $70 \mathrm{~mm}$ long) were machined on the top plate of the cooling water chamber, and five narrow channels $(1.2 \mathrm{~mm}$ wide, 1.2 $\mathrm{mm}$ deep, and $70 \mathrm{~mm}$ long) were machined in the five wide channels. The width of the narrow channels was just the size that the LMS-gels could be set without any clearance. Thus, wide channels were made to prevent the sample solutions from overflowing out of the channels. Samples were applied in the narrow channels using a micropipette, and then the stringsupported gels were accommodated there.

To prevent the LMS-gels from drying during IEF, the narrow channels were covered with acrylic blocks ( $10 \mathrm{~mm}$ wide, $5 \mathrm{~mm}$ high, and $70 \mathrm{~mm}$ long) by incasing the covers into the wide channels. The LMS-gels were directly connected to electrodes by pressing sections of $c a$. $0.5 \mathrm{~mm}$ at two ends of each LMS-gel under copper blocks, which were wrapped with platinum foil. The cooling water was controlled at $10^{\circ} \mathrm{C}$, and IEF was conducted in an atmosphere of nitrogen to eliminate the effect of $\mathrm{CO}_{2}$ in the air. IEF was run at a fixed current until the voltage increased to the desired value, and continued at the desired fixed voltage until the end of IEF (see Fig. 4C).

\section{pH gradient measurements}

The isoelectrically focused LMS-gels were cut into $5 \mathrm{~mm}$ sections, and then the gel sections were extracted with $25 \mu \mathrm{L}$ degassed distilled water in individual vials in an atmosphere of nitrogen for $1 \mathrm{~h}$. The $\mathrm{pH}$ values of the extracts in the vials were measured using a pH meter (B-212, Horiba, Japan).

\section{Second-dimensional electrophoresis}

Equilibration and second-dimensional electrophoresis were performed essentially as described by O'Farrell ${ }^{1}$ with some modifications. Since the LMS-gels were much thinner than those used by O'Farrell, the equilibration time was decreased to $40 \mathrm{~min}$ in the present study. To minimize the possible loss of 


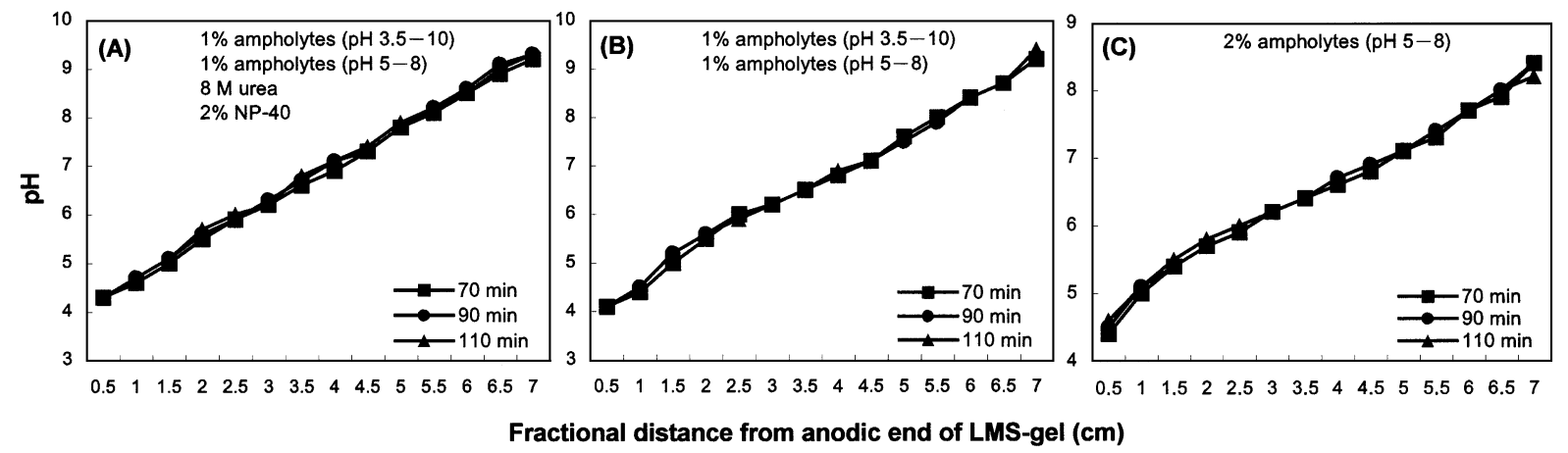

Fig. 3 Effect of the IEF time on the $\mathrm{pH}$ gradients. The LMS-gels used had a concentration of $2.5 \%$ $\mathrm{T}(5.4 \% \mathrm{C})$. The solutions for incubating the LMS-gels contained $10 \%(\mathrm{v} / \mathrm{v})$ glycerol in addition to the reagents noted in the individual graphs. IEF was conducted at a constant current of $0.09 \mathrm{~mA} / \mathrm{gel}$ until a voltage of $900 \mathrm{~V}$ was reached, and continued at the voltage of $900 \mathrm{~V}$ until the end of IEF.
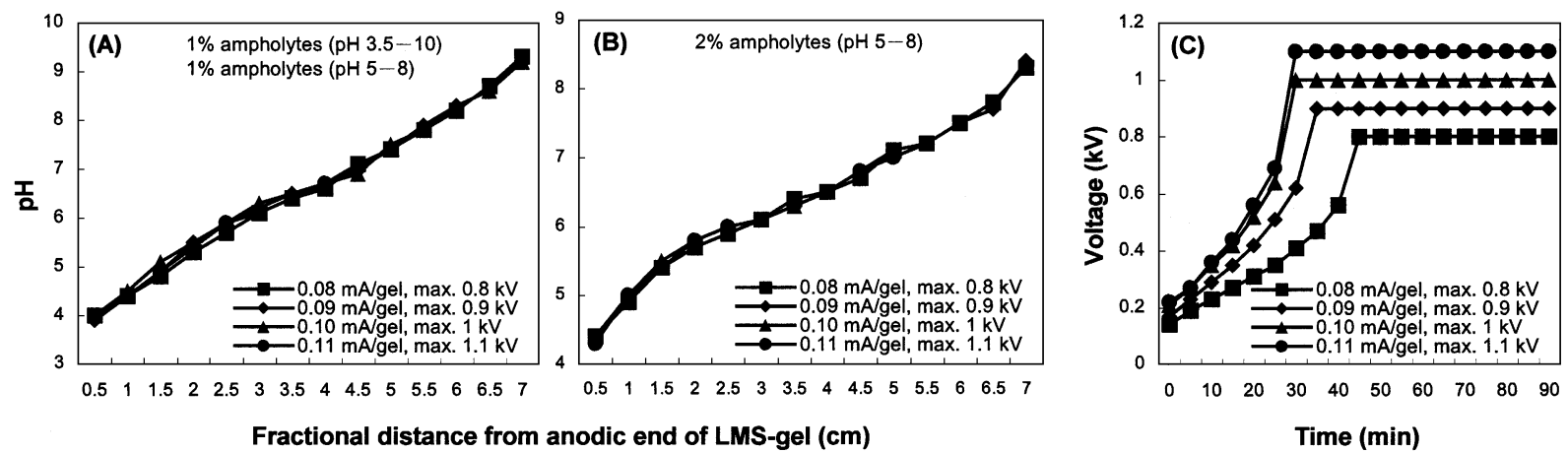

Fig. 4 Effect of the voltage on the $\mathrm{pH}$ gradients (A and $\mathrm{B}$ ) and voltage changes as a function of the IEF time at different currents (C). The LMS-gels and the solutions for incubating the LMS-gels were as described in Fig. 3.

large proteins during stacking, the stacking gel $(8 \mathrm{~cm}$ wide, 1 $\mathrm{cm}$ long, and $1 \mathrm{~mm}$ thick) was diluted to $2.5 \% \mathrm{~T}(2.6 \% \mathrm{C})$. The resolving gel was $8 \mathrm{~cm}$ wide, $6.5 \mathrm{~cm}$ long, and $1 \mathrm{~mm}$ thick, and had a uniform concentration of $9 \% \mathrm{~T}(2.6 \% \mathrm{C})$. Seconddimensional electrophoresis was run at a constant current of 25 $\mathrm{mA} / \mathrm{gel}$. Staining was carried out using a commercially available silver staining kit.

\section{Sample preparation}

To evaluate the new IEF system, three colored proteins (bovine blood hemoglobin, bovine heart cytochrome $c$, and spirulina $c$-phycocyanin) were used. The three proteins were dissolved in a solution of $2 \%$ polyoxyethylene (9) octylphenyl ether (NP-40), 30\% glycerol, and 1\% CAs. A chicken skeletal muscle (pectoralis major) extract was also used as a sample to evaluate the 2-DE performance using the LMS-gels. The sample preparation was as follows. Fresh muscle of $c a .1 .0 \mathrm{~g}$ was minced and homogenized in $15 \mathrm{~mL}$ of a solution containing $8 \mathrm{M}$ urea, $1 \mathrm{M} \mathrm{KI}, 0.1 \mathrm{mM} N^{\alpha}$-tosyl-L-lysine chloromethyl ketone hydrochloride (TLCK), 2\% NP-40, and $10 \% \quad \beta$ mercaptoethanol. The homogenate of $3 \mathrm{~mL}$ was dialyzed for 3 $\mathrm{h}$ against three changes of a solution containing $5 \mathrm{M}$ urea, $2 \mathrm{M}$ thiourea, and $2 \% \mathrm{NP}-40$ at $0^{\circ} \mathrm{C}$, and centrifuged at $14000 \mathrm{rpm}$ for $15 \mathrm{~min}$. The supernatant was used as the resultant sample for IEF.

\section{Reagents}

Acrylamide persulfate, Ampholine pH 3.5 - 10.0, Ampholine pH 5.0 - 8.0, $\beta$-mercaptoethanol, and silver staining kit for proteins were from Amersham Pharmacia Biotech (Uppsala, Sweden). TEMED, glycine, agarose, glycerol, Tris base, sodium dodecyl sulfate (SDS), NP-40, urea, potassium iodide, and TLCK were from Wako Pure Chemicals (Osaka, Japan). Thiourea, bovine blood hemoglobin, and bovine heart cytochrome $c$ were from Sigma (St. Louis, MO). Spirulina $c$-phycocyanin was from Tokai Sangyo Ltd. (Tokyo, Japan). All of the reagents for IEF were ultrapure, or specially manufactured for the use in gel electrophoresis, since IEF is very sensitive to impurities.

\section{Results and Discussion}

\section{Property of LMS-gels}

First, the multifilaments used for the present purpose should meet the following requirements: (1) It is important to make the volume ratio of polyacrylamide gel to a string in the LMS-gel as high as possible, since the string is ineffective to separation, and can cause adverse effects on the width of protein bands and the sample-loading capacity. In the present work, the ratio of gel to string was measured to be $9 \%$. (2) The material of the filaments should not contaminate analyzed samples, and should have no fixed negative charges on its surface, since fixed negative charges may distort the carrier ampholyte (CA)-generated $\mathrm{pH}$ gradients during IEF. ${ }^{18}$

Second, as described in Experimental section, the solution for 


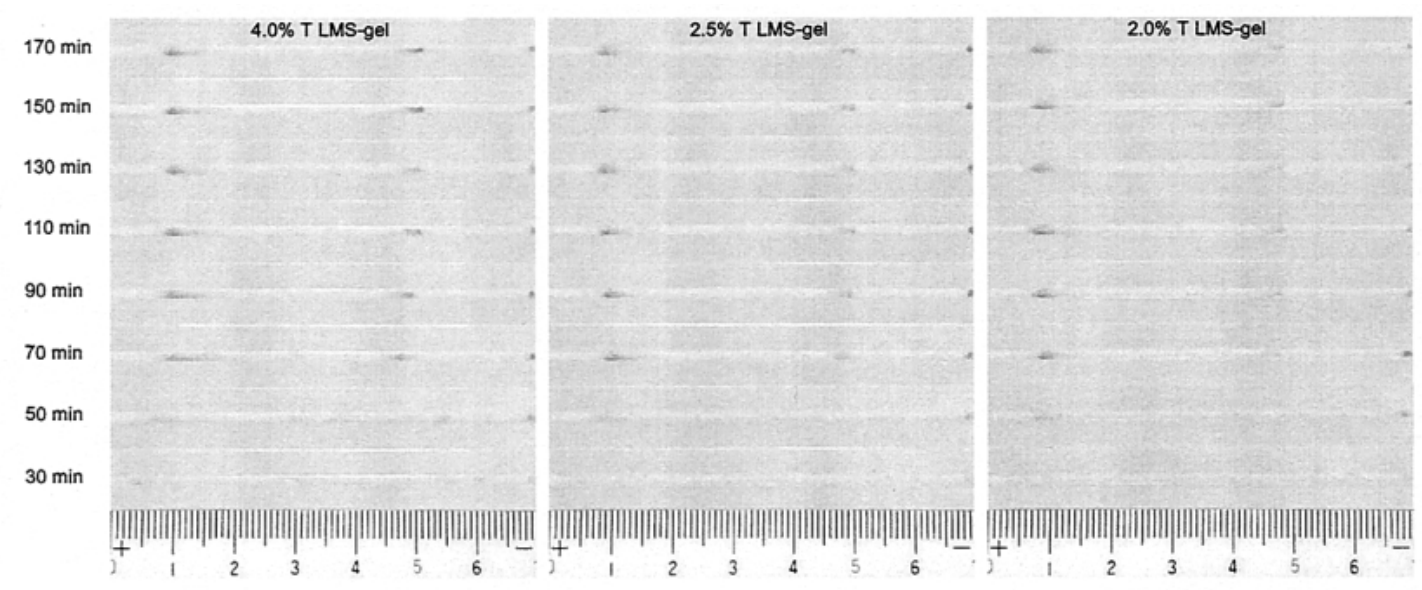

Fig. 5 IEF of colored proteins using LMS-gels of different concentrations. The solution for incubating the LMS-gels contained $1 \%(\mathrm{v} / \mathrm{v})$ ampholytes of $\mathrm{pH} 3.5-10,1 \%(\mathrm{v} / \mathrm{v})$ ampholytes of $\mathrm{pH}$ $5-8,2 \%(\mathrm{v} / \mathrm{v}) \mathrm{NP}-40$, and $10 \%(\mathrm{v} / \mathrm{v})$ glycerol. The power for running IEF was applied as described in Fig. 3. The proteins were dissolved with a proper amount of the solution for incubating the LMSgels, and the amounts of individual proteins loaded onto each LMS-gel were identical: $\sim 16 \mu \mathrm{g} c$ phycocyanin (MM: $\sim 264 \mathrm{kDa}$, pI: $\sim 4.3$, the left bands), $\sim 70 \mu \mathrm{g}$ hemoglobin (MM: $\sim 67 \mathrm{kDa}$, pI: $\sim 7.2$, the middle bands), $\sim 32 \mu \mathrm{g}$ cytochrome $c$ (MM: $\sim 13 \mathrm{kDa}$, pI: $\sim 9.6$, the right bands).

casting LMS-gels did not contain any reagents, but acrylamide and $N, N^{\prime}$-methylenebisacrylamide; instead, the polymerized LMS-gels were incubated with a solution containing the necessary reagents for IEF, such as chaotropes, detergents and CAs, after being washed with distilled water. This procedure is a little different from that for conventional IEF gels, in which all of the necessary reagents for IEF are pre-included in the IEF gel solutions. The procedure variation in the present study arose from an observation of ours that, if the chaotropes $(6 \mathrm{M}$ urea and $2 \mathrm{M}$ thiourea) and surfactants were present in the IEF gel solution, polymerization could not take place when preparing the LMS-gels lower than $2.5 \% \mathrm{~T}$. In fact, it has been reported before that thiol compounds, such as thiourea, can inhibit acrylamide polymerization.

In addition, it should be pointed out that the LMS-gel used in the present study is different from the threaded tube gel reported by Patton et al. in 1990. ${ }^{19}$ The latter gel was virtually the conventional-type tube gel, being strengthened by the thread. Furthermore, the thread used by Patton et al. cannot load a sufficient amount of super-soft gel on it.

\section{Stability of $\mathrm{pH}$ gradients}

In general, CA-generated $\mathrm{pH}$ gradients suffer from "cathodic drift" and a "plateau phenomenon"; these phenomena become severe with a prolonged focusing time and increased voltage in conventional IEF systems. ${ }^{20}$ To evaluate the stability of the $\mathrm{pH}$ gradient of the new IEF system, the $\mathrm{pH}$ values of each $5 \mathrm{~mm}$ section of the LMS-gels were measured. The obtained results are given in Fig. 3 and Figs. 4 A and B, while Fig. 4C shows the changes in the applied voltage as a function of the focusing time at different currents.

It can be observed that the $\mathrm{pH}$ gradients exhibit an essentially linear distribution along the gels, and an excellent stability in all cases. The stability at an IEF time longer than 110 min was not examined, since it was demonstrated that 110 min was ample for equilibrium IEF of proteins up to $264 \mathrm{kDa}$ with the present IEF system. In fact, the excellent stability can last until a focusing time of up to $170 \mathrm{~min}$ (Fig. 5). Several hypotheses have been advanced to explain the CA-generated $\mathrm{pH}$ gradient decay in conventional CA-based IEF systems, and among them the most accepted view, today, is that the major cause for the $\mathrm{pH}$ gradient decay during IEF is electroendosmotic flow generated by fixed charges in the gel matix. ${ }^{18}$ In most conventional CA-based IEF systems, IEF gels are typically prepared in glass tubes, and IEF is carried out in-tube. The internal surface of the glass tubes for housing the IEF gels can be negatively charged under basic conditions, and thus probably leads to a $\mathrm{pH}$ gradient instability. In the present IEF system, the gel preparation and IEF were carried out without glass tubes being used; therefore, the possible effects of glass on the $\mathrm{pH}$ gradients were eliminated. In addition, whatever the cause for the $\mathrm{pH}$ gradient decay in conventional CA-based IEF systems, it is a significant fact that the decay can be greatly minimized by eliminating the cathode electrolyte reservoir toward which the drift takes place, as reported by Hunter. ${ }^{21}$ This means that the electrode solutions universally used in the current CA-based IEF systems have deleterious effects on CA-generated $\mathrm{pH}$ gradients. In the new IEF system, such effects were thoroughly eliminated by eliminating both the cathode and anode solutions. Additionally, small free ions in the IEF gels, arising from the use of $\left(\mathrm{NH}_{4}\right)_{2} \mathrm{~S}_{2} \mathrm{O}_{8}$ and an impurity of the reagents, also have adverse effects on the $\mathrm{pH}$ gradient profiles. In the present study, such an effect was minimized by soaking the gels in distilled water for a long time prior to use for IEF. Therefore the excellent stability of the $\mathrm{pH}$ gradients in the present study should be attributed to the combined effect of the measures we took to improve the $\mathrm{pH}$ gradient stability.

For CAs of $\mathrm{pH} 3.5-10$, the measured $\mathrm{pH}$ gradients ranged from 4 to 9.3 (Fig. 3B and Fig. 4A), and were slightly narrower than the $\mathrm{pH}$ range quoted by the manufacturer. The $\mathrm{pH}$ gradients obtained using the gels containing urea and NP-40 (Fig. 3A) were slightly narrower than those achieved using gels without urea and NP-40 (Fig. 3B), indicating that urea and NP40 have only a small effect on $\mathrm{pH}$ gradient formation. These two observations seem to be universal for CA-generated $\mathrm{pH}$ gradients. ${ }^{1}$ For CAs of pH $5-8$, however, the measured ranges of $4.5-8.3$ (Fig. 3C and Fig. 4B) are much wider than the quoted $\mathrm{pH}$ range. This may be caused by the impurity of the CAs used in the present study.

It should be pointed out that, despite the $\mathrm{pH}$ gradient stability 


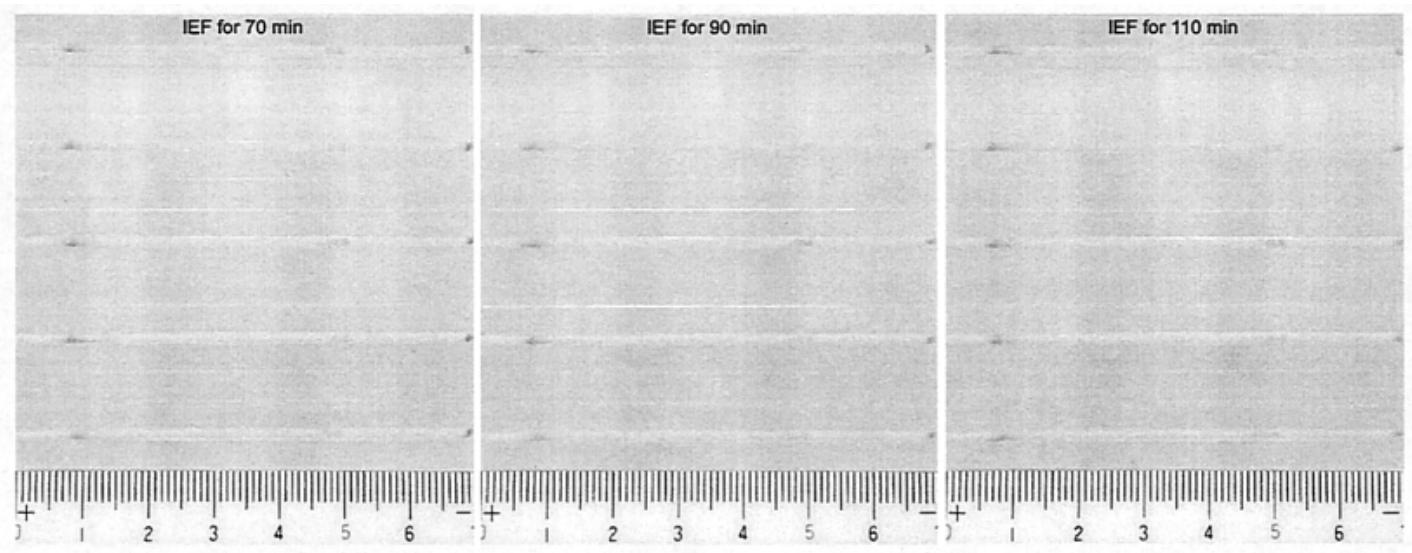

Fig. 6 IEF of colored proteins using LMS-gels prepared in different runs. The legend is the same as that for Fig. 5, except that the LMS-gels had an identical concentration of $2.5 \% \mathrm{~T}$.

at $0.11 \mathrm{~mA} / \mathrm{gel}$, it was found that the LMS-gels became somewhat dry at currents of more than $0.11 \mathrm{~mA} / \mathrm{gel}$; therefore, IEF was conducted at 0.1 or $0.09 \mathrm{~mA} / \mathrm{gel}$ in the following experiments. Meanwhile, to solve the problem of water loss from the LMS-gels during IEF, experiments on modifying the present IEF apparatus are currently underway in our laboratory.

\section{IEF time}

The IEF time depends on several parameters, such as the gel dimensions, porosity of the gel matrix, interval of the $\mathrm{pH}$ gradient, temperature, applied power, and analyzed samples. Generally, IEF to steady state needs more than $10 \mathrm{~h}$, including the time for sample loading, for the currently existing IEF systems. ${ }^{16}$

In the present study, the IEF time with the new IEF system was examined for LMS-gels of $4.0 \% \mathrm{~T}, 2.5 \% \mathrm{~T}$ and $2.0 \% \mathrm{~T}$ using three naturally colored proteins; the data are presented in Fig. 5, which were obtained by taking photographs at different IEF times. These proteins were selected for this experiment because they not only can be directly visualized after being focused, but also cover a wide range of molecular mass (13 $264 \mathrm{kDa})$ and $\mathrm{pI}(4.3$ - 9.6).

From Fig. 5, three observations can be made. (1) In all cases, the focusing times are not longer than $110 \mathrm{~min}$, even for the large protein of $c$-phycocyanin $(264 \mathrm{kDa})$, and much shorter than that with the currently existing IEF systems. (2) The focusing times, which are 90 and $70 \mathrm{~min}$ for the $2.5 \% \mathrm{~T}$ and $2 \%$ $\mathrm{T}$ gels, respectively, are further shortened compared to that with the $4.0 \% \mathrm{~T}$ gel. This is because the gels of lower concentrations have larger pore sizes, and thus produce a weaker resistance to the migration of proteins. (3) All of the protein bands can keep their fixed positions after being focused. This observation, once again, demonstrated the excellent stability of the $\mathrm{pH}$ gradients used in the present study. This also indicates that true equilibrium IEF had been achieved within the IEF times of 110 $\mathrm{min}, 90 \mathrm{~min}$, and $70 \mathrm{~min}$ for the gels of $4.0 \% \mathrm{~T}, 2.5 \% \mathrm{~T}$ and $2.0 \% \mathrm{~T}$, respectively.

Protein loading capacity of LMS-gels of different concentrations

A high protein loading capacity is desirable, especially in preparative gel electrophoresis. From Fig. 5, it can be appreciated that, in spite of the identical amounts of the applied proteins, the focused protein bands in the gels of lower concentrations are narrower than those in the gels of higher concentrations, indicating that the gels of lower concentrations can load more proteins than the gels of higher concentrations. Reghetti and Gelfi $^{22}$ also reported that the dilution of the polyacrylamide matrix from $6 \% \mathrm{~T}$ to $3 \% \mathrm{~T}$ afforded a doubling of the sample amount that could be loaded. If the gel matrix was further diluted below the critical level of $3 \% \mathrm{~T}$, the amounts of proteins that could be loaded increased exponentially, instead of linearly. Undoubtedly, such increments in the sample loads are attributed to the enlarged gel porosity of the diluted gel matrix. Therefore, the use of LMS-gels of lower concentrations is a simple and effective way to achieve a high sample loading capacity. Of course, gels of larger dimensions can also improve the sample loading capacity, but they suffer from a longer IEF time and a loss in the resolution power.

\section{Gel-to-gel reproducibility}

The gel-to-gel reproducibility was examined for LMS-gels using three naturally colored proteins; the results are presented in Fig. 6. IEF of the three proteins was conducted using five LMS-gels prepared in different runs, and pictures were taken at different IEF times. It can be observed that the five LMS-gels produced very similar band positions for the three proteins at different IEF times, demonstrating that the gel-to-gel reproducibility is reliable.

\section{Application of the new IEF system to 2-D PAGE}

The new IEF system was finally applied to 2-D PAGE of proteins using LMS-gels of $4.0 \% \mathrm{~T}$ and $2.5 \% \mathrm{~T}$ in the first dimension; the data obtained are shown in Fig. 7. The sample used was a chicken skeletal muscle extract. This sample was selected because it contained many high-molecular-mass and low-solubility proteins, such as myosin heavy chains, Cproteins, M-proteins that are difficult to be detected using the existing 2-D PAGE systems. ${ }^{9-11}$ For a comparison, the sampleload, running and staining conditions were rigorously identical in the two cases.

It can be appreciated that the 2-DE protein map obtained using the $2.5 \% \mathrm{~T}$ LMS-gel displays a much higher staining intensity than that with the $4.0 \%$ T LMS-gel, and even many protein spots on the map obtained using the $2.5 \% \mathrm{~T}$ LMS-gel cannot be found on the map obtained using the $4.0 \%$ T LMS-gel with the present amount of sample load. Importantly, highmolecular-weight proteins of more than $100 \mathrm{kDa}$, which should include myosin heavy chains $(\sim 200 \mathrm{kDa})$, can also be clearly found on the map obtained by using $2.5 \% \mathrm{~T}$ LMS-gel with a 


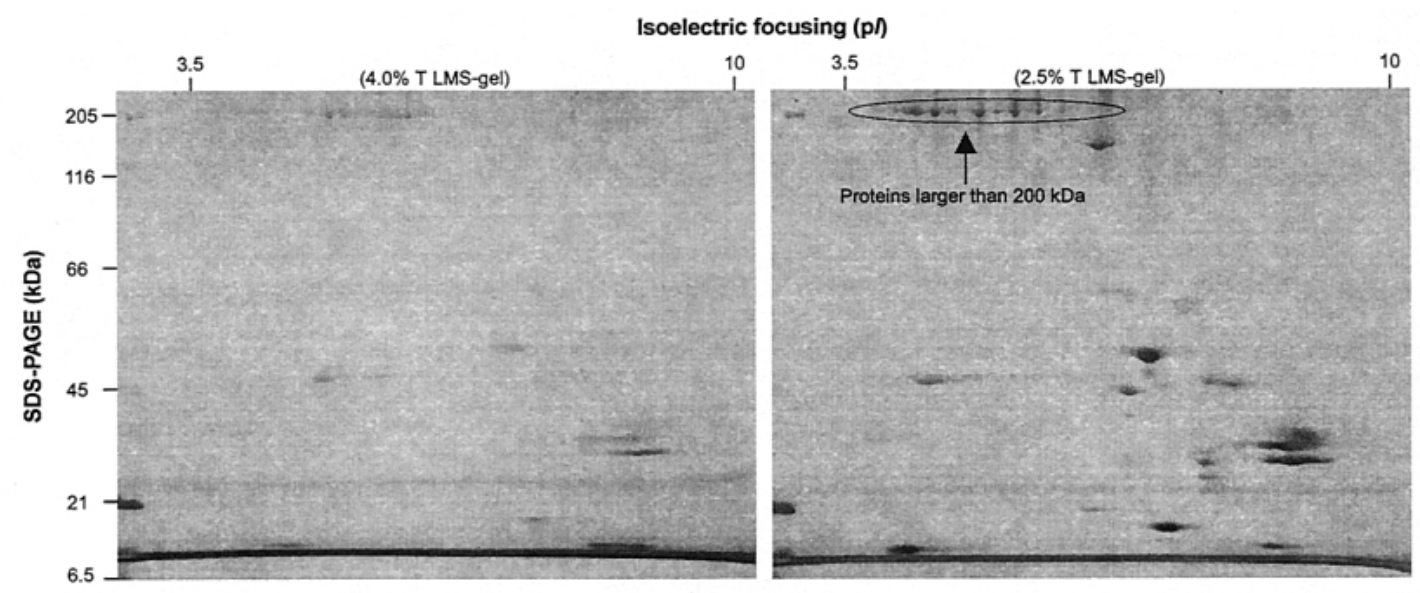

Fig. 7 2-D PAGE of chicken skeletal muscle extract using the LMS-gels of $4.0 \% \mathrm{~T}$ and $2.5 \% \mathrm{~T}$ in the first dimension. The amount of the extract loaded onto each LMS-gel was $5 \mu \mathrm{L}$. IEF was run at a constant current of $0.09 \mathrm{~mA} / \mathrm{gel}$ until a voltage of $1200 \mathrm{~V}$ was reached, and continued at a voltage of $1200 \mathrm{~V}$ for $1 \mathrm{~h}$.

high staining intensity. Hirabayashi ${ }^{10}$ reported that he had tried several conventional methods, and no myosin heavy chains were found on the obtained 2-D maps when he used polyacrylamide gels in the first dimension. It can be included that LMS-gels of lower concentrations can significantly improve the protein entry into the IEF gels during sample loading and the protein transfer from the first-dimensional gel to the second one.

However, it has not been certain whether the spots ranging horizontally at the level of $c a .200 \mathrm{kDa}$ on the obtained 2-D maps represent a group of proteins similar in nature, or unfocused myosin heavy chains. Considering that muscle proteins are mostly structural ones that easily aggregate with each other, ${ }^{10}$ especially at low ionic strengths, they may also represent polymers of some small proteins. No matter what these spots represent, importantly, it is a fact that large proteins of up to $260 \mathrm{kDa}$ (e.g., c-phycocyanin in Figs. 5 and 6) can be significantly focused and transferred from the first-dimensional to the second-dimensional gels by using the super-soft gel of $2.5 \% \mathrm{~T}$.

\section{Conclusion}

The IEF system described in the present study is superior to the existing ones for the following reasons: (1) Super-soft and tough gels (LMS-gels) can be easily prepared by casting polyacrylamide gel down to $2.0 \% \mathrm{~T}$ in multifilaments by means of the home-made setup described above. (2) The LMS-gels are very tough, though they are super-soft, and thus can be handled easily in spite of the low concentration. (3) The IEF apparatus described in the present study eliminates the need for electrode solutions that are necessary in the existing CA-based IEF systems. This not only simplifies IEF runs, but also has a great contribution to the stability of the $\mathrm{pH}$ gradients. (4) In the present IEF system, IEF can be performed freely from glass tubes, and thus the adverse effects of glass tubes on the stability of CA-generated $\mathrm{pH}$ gradients in the existing IEF systems can be thoroughly eliminated. (5) Because of eliminations of the adverse effects of electrode solutions, glass tubes and free ions in IEF gels, excellent stability of CA-generated $\mathrm{pH}$ gradients along the LMS-gels can be maintained for a sufficiently long duration, and thus true equilibrium IEF can be achieved with the present system. This is known to be impossible for the existing CA-based IEF systems. (6) As good analytical features of the super-soft LMS-gels, IEF time, protein entry into the LMS-gels, and protein transfer from the first-dimensional to the seconddimensional gels can be greatly improved over the IEF gels of $4 \% \mathrm{~T}$, which are currently used universally.

In addition, since super-thin LMS-gels can be easily prepared in the present IEF system, it has very good potentials to significantly improve the resolution of 2-D PAGE, and to be used in miniaturized 2-D PAGE systems for fast separation of proteins.

\section{Acknowledgements}

The authors thank Dr. Toshio Eiki for his help in preparing the chicken skeletal muscle extract. This work was partially supported by the Grant-in-Aid for Scientific Research on Priority Area (No. 13124201), Creation of Micro Chemo Mechatronics, from the Ministry of Education, Culture, Sports, Science and Technology, Japan.

\section{References}

1. P. H. O'Farrell, J. Biol. Chem., 1975, 250, 4007.

2. S.-E. Ong and A. Pandey, Biomol. Eng., 2001, 18, 195.

3. T. Rabilloud, Proteomics, 2002, 2, 3.

4. G. Piperno, B. Huang, Z. Ramanis, and D. J. L. Luck, J. Cell Biol., 1981, 88, 73 .

5. C. Adessi, C. Miege, and T. Rabilloud, Electrophoresis, 1997, 18, 127.

6. G. Candiano, L. Musante, M. Bruschi, G. M. Ghiggeri, B. Herbert, F. Antonucci, and P. G. Righetti, Electrophoresis, 2002, 23, 292.

7. J. L. Harry, M. R. Wilkins, N. H. Packer, A. A. Gooley, and K. L. Williams, Electrophoresis, 2000, 21, 1071.

8. E. Olivieri, B. Herbert, and P. G. Righetti, Electrophoresis, 2001, 22, 560.

9. M. Oh-Ishi, M. Satoh, and T. Maeda, Electrophoresis, 2000, 21, 1653.

10. T. Hirabayashi, Electrophoresis, 2000, 21, 446.

11. M. Oh-Ishi and T. Maeda, J. Chromatogr. B, 2002, 771, 49. 
12. T. Rabilloud, C. Adessi, A. Giraudel, and J. Lunardi, Electrophoresis, 1997, 18, 307.

13. B. R. Herbert, M. P. Molloy, B. J. Walsh, A. A. Gooley, W. G. Bryson, and K. L. Williams, Electrophoresis, 1998, 19, 845.

14. M. Chevallet, V. Santoni, A. Poinas, D. Rouquie, A. Fuchs, S. Kieffer, M. Rossignol, J. Lunardi, J. Garin, and T. Rabilloud, Electrophoresis, 1998, 19, 1901.

15. A. Gorg, C. Obermaier, G. Boguth, and W. Weiss, Electrophoresis, 1999, 20, 712.

16. A. Gorg, C. Obermaier, G. Boguth, A. Harder, B. Scheibe, R. Wildgruber, and W. Weiss, Electrophoresis, 2000, 21, 1037.
17. J. Klein, G. Harding, and E. Klein, J. Proteome Res., 2002, 1,41 .

18. P. G. Reghetti and C. Macellni, J. Biochem. Biophys. Methods, 1982, 5, 1.

19. W. F. Patton, M. G. Pluskal, W. M. Skea, J. L. Buecker, M. F. Lopez, R. Zimmermann, L. M. Belanger, and P. D. Hatch, BioTechniques, 1990, 8, 518.

20. L. E. M. Miles and J. E. Simmons, Anal. Biochem., 1972, 49, 109.

21. L. Hunter, Anal. Biochem., 1978, 89, 279.

22. P. G. Righetti and C. Gelfi, J. Biochem. Biophys. Methods, 1984, 9, 103 